\title{
Efficiency evaluation of a specialist in the field of optical design during education and work
}

\author{
Irina Livshits ${ }^{1, *}$ and Aleksandr Petukhov ${ }^{1}$ \\ ${ }^{1}$ ITMO University, 49 Kronverksky, Saint-Petersburg, Russia, 197101
}

\begin{abstract}
Our goal is to evaluate the efficiency of a specialist in the field of optical design. The classification of specialists is given depending on their level of education and work experience in the field of optical design. The analysis of factors that determine the efficiency of the specialist is performed, on the basis of which the equation for calculating efficiency is derived. As an example, we present empirical data for calculating the efficiency of some specialists.
\end{abstract}

\section{Introduction}

The creation of optical devices is closely related to the development of technologies. In our century, the pace of their improvement has accelerated so much that specialists of one generation become participants in several technical revolutions. Such events include, for example, the introduction of computer technology in optical calculations in the 60 s of the 20th century [1], the improvement of calculation technologies (Forbes aspherics [2] - the beginning of the 21 st century, etc.) and the manufacture of aspherical surfaces, the use of new materials [3], the creation of methods for calculating and manufacturing free-form surfaces [4], the use of artificial intelligence in optical design [5], etc.

The desire of specialists to remain updated is the main motivation for continuing their education in the field of optical design and related fields. Therefore, these specialists are constantly trained, improved, conduct research, analyze the results obtained, exchange them at conferences and in various publications.

\section{Specialist classification}

The community of specialists is very heterogeneous in its composition. The article provides a classification of specialists depending on their level of education and work experience in the field of optical design, please, see Table 1 .

Table 1. Classification of optical design specialists.

\begin{tabular}{|c|c|c|c|}
\hline $\mathbf{N}$ & $\begin{array}{c}\text { Level of } \\
\text { specialists }\end{array}$ & $\begin{array}{c}\text { Time of } \\
\text { study/work, } \\
\text { years }\end{array}$ & $\begin{array}{c}\text { Indicator of } \\
\text { professional level }\end{array}$ \\
\hline 1 & beginner & $3-5$ & 0.3 \\
\hline 2 & advanced & $6-20$ & 0.7 \\
\hline 3 & expert & $>20$ & 1 \\
\hline
\end{tabular}

A beginner is a student or employee who has recently graduated from a University and started working. He/she already has the theoretical knowledge and set of necessary skills to be an optical system design engineer.

Advanced specialist is an employee who feels confident in the profession. Such an employee applies technical skills freely. Usually he/she specializes in one of the types of optical systems.

Expert is a specialist who already has a lot of experience behind him. Such an employee can easily calculate any type of system. He/she is the generator of new solutions and schemes.

\section{Efficiency equation}

We live in the age of digital technologies, when most phenomena and events, organizations, etc. are classified, and then their ratings are determined.

We propose to represent the efficiency of specialists working as optical designers as a number that can be compared. This can be useful, for example, for employment or when choosing an invited speaker for a conference, choosing a research supervisor and opponent, and so on. There are known attempts to classify specialists in such systems as ORCID [6], Research Gate [7], ResearcherID [8], and some others.

The information contained in these systems was partially used by us, but we set the task of a deeper analysis of the efficiency of specialists in one subject area-optical design. As a result of this assessment, we have obtained expressions that take into account the main factors of efficiency of a University graduate throughout his/her career - from a student to an expert.

The number of publications, patents, and monographs is taken into account. We also consider it important to evaluate aspects that have not been considered before - "loyalty to the profession" and the indicator of creativity. 
It seems necessary to take into account the factors defined by equations (1-3):

$$
\begin{gathered}
O D S=L^{*} \sum_{i=1}^{3} P_{i} * T_{i}+C \\
L=\frac{N_{p}}{N_{a}} \\
C=K_{p} * M_{p}+K_{a} * M_{a}+K_{m} * M_{m}
\end{gathered}
$$

where:

$O D S$ - efficiency of a specialist in the field of optical design;

$L$ - loyalty to the profession;

$\mathrm{Np}$ - number of years of work by profession;

$\mathrm{Na}$ - total work experience;

$P i$ - indicator of professional level;

$T i$ - number of years at level I;

$C$ - creativity indicator;

$M p$ - number of patents;

$K p$ - the weight ratio of patents;

$M a$ - number of articles;

$\mathrm{Ka}$ - the weight ratio of articles;

$\mathrm{Mm}$ - number of monographs;

$\mathrm{Km}$ - the weight ratio of monographs.

We analyzed the effectiveness of two-generation opticians in the Soviet Union and Russia and determined the values of the coefficients of equation (1), which are used to calculate the creativity indicator $(K p=0.2$; $K a=0.1 ; K m=1)$.

Table 2 shows an example of calculating the effectiveness of existing specialists, but the names and surnames have been changed. Ivanov is a second-year student with one patent and one article. Petrov is a young specialist, studied for 5 years (two years as an electrical engineer and 3 years as an optical design student), works for two years by profession, he has two patents and four articles. Ivanova is a specialist, she has studied optical design for 5 years, works for 5 years in her specialty, she has 5 articles and 5 patents. Petrova is an expert, she has studied optical design for 5 years, she has been working for 20 years in her specialty, she has 50 patents, 100 articles and 5 monographs.

Table 2. ODS calculation examples.

\begin{tabular}{|c|c|c|c|c|c|}
\hline $\mathbf{N}$ & Name(sex) & $\mathbf{L}$ & $\sum_{i=1}^{3} P_{i} * T_{i}$ & $\mathbf{C}$ & ODS \\
\hline 1 & Ivanov(m) & 1 & 0.3 & 0.3 & 0.6 \\
\hline 2 & Petrov(m) & 0.6 & 2.1 & 0.8 & 2.0 \\
\hline 3 & Ivanova(f) & 1 & 5 & 1.5 & 6.5 \\
\hline 4 & Petrova(f) & 1 & 15 & 25 & 40 \\
\hline
\end{tabular}

Thus, from table 2 it can be seen that ODS for a beginner (Ivanov, Petrov), advanced specialist (Ivanova) and expert (Petrova) differs seriously. The idea of including the creativity into equation (1) looks important as creativity has sometimes more value than even professional skills.
In terms of developing the presented idea, it is desirable to develop a number of tests that are appropriate for this subject area. To evaluate the effectiveness of a student, graduate, and post-graduate student, you can use the results of certification exams.

In conclusion, it should be noted that equations (1-3) can be used in other professional subject areas, provided that coefficients are identified in a specific subject area.

\section{References}

1. I.L. Livshits, D.C. Dilworth, Advanced Optical Technologies, 7, 335 (2018)

2. http://www.opticsinfobase.org/abstract.cfm?URI=O FT-2010-OTuA6

3. https://doi.org/10.1364/OME.393986

4. J. Miñano, P. Benitez, et al. Proc. SPIE. 10590, International Optical Design Conference (2017)

5. Р.В. Анитропов, И.Л. Лившиц, Д.В. Свищук, Известия высших учебных заведений. Приборостроение, 53, 77 (2010)

6. https://orcid.org/

7. https://researchgate.net/

8. https//researcherid.com/ 